\title{
NUTRITION AND CANCER - SOME BIOCHEMICAL MECHANISMS
}

\author{
CHRISTINE M. WILLIAMS AND J. W. T. DICKERSON
}

Division of Nutrition, Department of Biochemistry, University of Surrey, Guildford GU2 5XH

\section{CONTENTS}

INTRODUCTION .

CHEMICAL CARINOGENESIS . . . . . . . . . . . . . . 76

NUTRITION AND THE AETIOLOGY OF CANCER . . . . . . 77

DIETARY FAT, MAMMARY TUMORIGENESIS AND HUMAN BREAST

CANCER .

INTRODUCTION

DIETARY FAT, ENERGY INTAKE AND MAMMARY TUMORIGENESIS . . $\quad 80$

BODY-WEIGHT, OBESITY AND HUMAN BREAST CANCER . . . . . . . 81

ALTERATIONS IN HORMONES IN RESPONSE TO DIETARY FAT INTAKE . . 83

ALTERATIONS IN MEMBRANE STRUCTURE AND FUNCTION . . . . . 84

COMMENT . . . . . . . . . . . . . . . . . . . . 86

MICRONUTRIENTS AND CANCER . . . . . . . . . . . 87

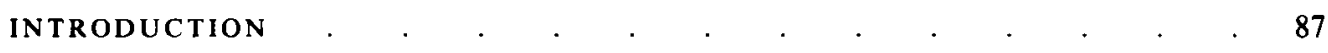

EPIDEMIOLOGICAL EVIDENCE . . . . . . . . . . . . . . . 87

Lung . . . . . . . . . . . . . . . . . . . . . 88

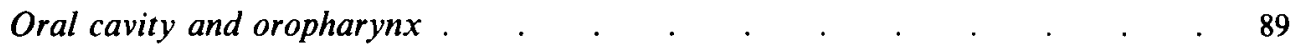

Oesophagus . . . . . . . . . . . . . . . . . . . . . 8

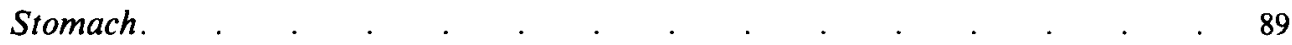

Bladder . . . . . . . . . . . . . . . . 90

Breast . . . . . . . . . . . . . . . . . . . . . 90

Prostate. . . . . . . . . . . . . . . . . . . 90

COMMENT .

EXPERIMENTAL EVIDENCE . . . . . . . . . . . . . . 91

Initiation and/or promotion . . . . . . . . . . . . . . . . . . . 91

Differentiation . . . . . . . . . . . . . . 91

Latency . . . . . . . . . . . . . . . . . . . . . . 92

Antioxidants . . . . . . . . . . . . . . . . . . . 92

Interrelationships with hormones . . . . . . . . . . . . . . . . . . 93

Other aspects. . . . . . . . . . . . . . . . . . . . . . . . . 93

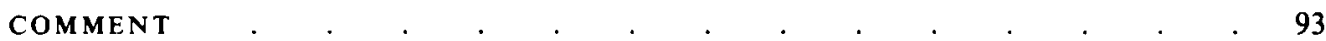

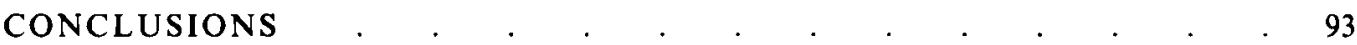

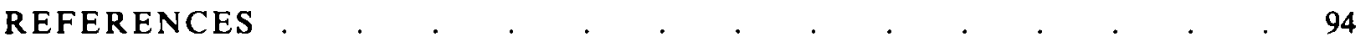




\section{INTRODUCTION}

The word 'cancer' is used to describe a large group of diseases characterized by the uncontrolled growth and spread of abnormal tissues. They arise in different organs and differ markedly from one another in their pattern of growth and spread. They may have different extrinsic causes reflected by differences in age, sex, occupational and racial incidence, and may result from different mechanisms of neoplastic change (Louis, 1978). Cancer itself is difficult to define, but the neoplastic diseases have in common their ability to destroy the host if attempts at eradication are unsuccessful. The malignant cell cannot yet be defined. Although it is well known what this cell does, and how it does what it does, the reason why is unknown (Becker, 1975).

The present review is concerned with the possible role of diet in the genesis and growth of cancer. We are thus concerned with the part that food constituents may play in the induction, promotion and growth of tumours. It is worth while considering the stages of chemical carcinogenesis before discussing the evidence which suggests that food, or more specifically, nutrition, may be involved. One reason for interest in nutrition in relation to cancer is the fact that some cancers are relatively common, and their treatment variable in its effectiveness. They are thus common causes of death, with their progress seemingly unrelenting. Nutrition is amenable to change and thus understanding the relationship between various dietary constituents and cancer offers scope for prevention. It is not possible to review possible relationships with tumours at all sites and more attention will be given to cancers of the breast, lung and digestive tract.

\section{CHEMICAL CARCINOGENESIS}

It is now generally accepted that the transformation of normal tissue cells into malignant tumour cells is a multi-stage process (Hicks, 1983a). The stages of chemical carcinogenesis include carcinogen metabolism, initiation and promotion, cell differentiation and tumour cell progression and tumour growth and development, and each stage may be affected by diet (Poirier, 1987).

Whilst considerable attention has been focused on the processes of initiation and promotion and the stages consequent upon them, it is important to appreciate that some compounds that are referred to as 'carcinogens' are, in fact, pro-carcinogens, and there is therefore a possibility that dietary components may affect the carcinogenicity of these compounds by interfering with their conversion to ultimate carcinogens.

The early work which led to the development of our knowledge of the processes of 'initiation' and 'promotion' was done by Rous and Berenblum and their colleagues on mouse skin in the early 1940s (Hicks, 1983a). They showed that wounding or painting the skin with a corrosive compound, croton oil, greatly increased the tumour response to a previously administered low dose of the carcinogen, benzo( $\alpha$ )pyrene (BP). In this example, BP was said to act as the 'initiator' of carcinogenesis and croton oil or wounding as the 'promoter'. These processes, and the biochemical events that are associated with them, seem to be fundamental to our understanding of the possible role of dietary factors in relation to cancer. There is now good evidence that similar stages occur in many other epithelial organs, including oesophagus, stomach, colon, pancreas, liver, bladder, lung and mammary gland, and in cells in tissue culture.

'Initiation' involves the induction of a change in DNA, usually as a result of covalent reaction of a carcinogen with the DNA. The reaction is rapid, dose-related and can occur after a single exposure to the initiating compound. Few cells may be affected and the 
damage will not be evident unless other factors, known as 'promoters', further modify the cell.

'Promotion' takes place in two stages, is initially reversible and requires prolonged exposure of previously initiated cells. Although promoters act on normal cells they do not cause the development of a tumour unless the DNA of the cells has previously been damaged. Promotion involves changes at cell membranes. A stage- 1 promoter is a compound capable of activating protein kinase $C(E C 2.7 .1 .37)$ and the subsequent phosphorylation of macromolecules which regulate cellular functions. Stage-1 promoters do not cause tumorigenesis unless they can also induce the changes which characterize stage 2. Stage- 2 promotion involves the exposure of initiated, stage-1-induced cells to substances that are capable of exposing the hitherto latent tumour-producing properties of the cells. Stage- 2 promoters therefore induce enzymes involved in the synthesis of products involved in cell division. Although, again, the early work was done on mouse skin, the induction of ornithine decarboxylase (EC 4.1.1.17; ODC) and 5-adenosylmethionine decarboxylase (EC 4.1.1.50) have been reported to result from stage-2 promotion by a number of compounds, including growth-promoting hormones and by partial hepatectomy. ODC is the rate-limiting enzyme for the synthesis of the polyamines, putrescine, spermine and spermidine which function in the control of DNA, RNA and protein synthesis, and thus plays a key role in controlling cell division.

Free radical attack is probably the initial damage that begins the process of malignant transformation (Ames, 1979). Oxygen radicals and/or hydrogen peroxide, it has been suggested, may be generated by compounds or agents that act as promoters (Marx, 1983; Emerit et al. 1983). Such radicals have the capacity to interact with a wide variety of biological molecules, but because of their double bonds, unsaturated fatty acids are particularly vulnerable. The resultant products, lipoperoxides, are active compounds which react with many cellular compounds. They product cross-links with proteins (Funes et al. 1980) and damage cell-membranes (Weinstein et al. 1984). The lipoperoxide attack on DNA also leads to damage, despite the fact that promoters do not interact directly with DNA (Marx, 1983). Other molecules subject to peroxidation include the prostaglandins and leukotrienes, derivatives of arachidonic acid, which play a major role in cell growth and differentiation (Ohuchi \& Levine, 1980).

Metaplasia and abnormal changes in cells often occur during tumour development (Uriel, 1979). These changes may be prevented by dietary factors, particularly vitamin A and retinoids, which help to maintain epithelial cells in a state of normal differentiation. The possible role of vitamin $\mathrm{A}$ in preventing the development of cancer will be discussed later. It is characteristic of tumours that they grow. The part that dietary factors may play in inhibiting tumour growth and in strengthening the host's immunological defence will also be discussed.

\section{NUTRITION AND THE AETIOLOGY OF CANCER}

Interest in the potential role of diet in the aetiology of cancer emerged in the late 1960s when marked international variations in the number of deaths from cancer were reported (Miller, 1985). Studies of disease incidence in migrant populations suggested that these differences were not a function of genetic constitution since, for the most part, cancer incidence in migrant groups shifted from that of the country of origin to that of the host country. Doll \& Peto (1981) estimated that $80-90 \%$ of human cancers are caused by environmental factors, and that in the United States appropriate dietary changes might reduce cancer deaths by as much as $35 \%$. 
Epidemiological findings published during the 1970s showed that the strongest correlations between international food-consumption patterns and disease incidence (cross-cultural studies) were for cancers of the gastrointestinal tract and endocrine-related tumours, such as those of the breast, uterus, ovary and prostate. The most consistent reports were those showing strong positive associations between the consumption of total fat and death rates from breast and colon cancer (Correa, 1981), and negative associations between dietary fibre and colon cancer (Armstrong \& Doll, 1975). Strong associations were also found between a high consumption of nitrates and low consumption of vitamin $\mathrm{C}$, or fruit, and gastric cancers (Miller, 1985). Reports also began to emerge which suggested that vitamin $\mathrm{A}$, or its precursors found in red and green fruit and vegetables, may be protective against lung cancer (Peto et al. 1981). Consistently positive associations between the consumption of alcohol and oesophageal cancer were also reported (Chilvers et al. 1979).

In 1982 the US Committee on Diet, Nutrition and Cancer of the National Research Council considered reports of these associations to be sufficiently strong for the formulation of interim dietary guidelines likely to reduce the risk of cancer (Committee on Diet, Nutrition and Cancer, 1982). These guidelines included the recommendation that as a protection against the development of colon and breast cancers, dietary fat intake should be reduced from current levels of $40 \%$ of the energy intake to $30 \%$ and that consumption of fibre and fruit and vegetables should increase. However, reports of associations between the intake of fat and cancers of the breast and colon and between the intake of fibre and cancer of the colon obtained from cross-cultural studies have not been consistently supported by case-control studies carried out since 1982 (Byers, 1988; Berrino \& Muti, 1989). On the other hand, remarkably consistent findings have been obtained from both cross-cultural and case-control studies of the relationship between dietary vitamin A (or carotene) and lung cancer (Byers, 1988), and these appear to support strongly a protective role for dietary carotene (or a related component in fruit and vegetables) against lung cancer.

Lack of agreement between cross-cultural and case-control studies of associations between fat and fibre intakes and the incidence of cancers of the breast and colon have in part been attributed to inaccuracies in the methods available for assessing intakes of these dietary constituents in large numbers of individuals. The food-frequency questionnaire which is used as a standard method for assessing nutrient intakes in case-control studies is notoriously inaccurate for nutrients such as fat. Intake of this nutrient is obtained from a wide range of foods which may vary greatly in fat content and composition, depending on factors such as agricultural practice and manufacturing techniques, menus and cooking methods and food wastage. By comparison, micronutrients such as carotene are derived from more discrete elements of the diet and may be quantified more reliably by this method of dietary assessment. Recognition of these problems has led to much discussion of the limitations of current methods for assessing nutrient intakes in epidemiological case-control studies. (Freudenheim \& Marshall, 1988; Hill, 1989; Wahrendorf, 1989).

A number of recent critical reviews have addressed the need to develop biochemical markers of nutrient intake and in particular to develop markers which reflect the mechanism(s) by which nutrients may influence carcinogenesis (Byers, 1988; Berrino \& Muti, 1989). For example, mechanisms which have been proposed to explain the relationship between dietary fat intake and breast cancer include : alteration of membrane fatty acid composition, prostaglandin production, lipoperoxide generation, excessive hormonal stimulation, carcinogen activation and carcinogen storage, as well as energy effects of high-energy, high-fat diets. Biological markers of long-term fat intake may include membrane fatty-acid composition or urinary prostaglandin secretion, adiposity or serum hormones. However, it is unlikely that the appropriate markers can be identified 
until the underlying biological mechanisms are more clearly defined. This will require further experimental studies in animals and detailed small-scale clinical studies in humans; these studies are essential if further epidemiological investigations are to provide meaningful information.

In the following sections particular attention is given to the mechanisms by which dietary fat and antioxidant micronutrients may influence the incidence of breast, lung and gastrointestinal cancers, although the principles outlined may apply to effects of these nutrients at other sites also. Where relevant, comparisons between findings obtained from epidemiological and animal studies are drawn, and suggestions are made for the inclusion of appropriate dietary and biological markers in future studies of human populations.

\section{DIETARY FAT, MAMMARY TUMORIGENESIS AND HUMAN BREAST CANCER}

\section{INTRODUCTION}

Experimental diets high in fat $(>100 \mathrm{~g} / \mathrm{kg}$ ) have been shown to enhance tumorigenesis in spontaneous, carcinogen-induced, X-irradiation-induced and transplantable mammary tumours in both rats and mice (Welsch, 1987). Effects of high-fat diets are most marked when fed after initiation, and are equally marked in carcinogen-induced and transplantable tumour models. For these reasons tumour-enhancing effects of high-fat diets have been attributed to their actions on the promotional rather than the initiating phase of carcinogenesis. However, some studies (Dao \& Chan, 1983; Kritchevsky et al. 1984) have suggested that high-fat diets can also influence the initiation stage, since increased tumour incidence was seen in rats fed on high-fat diets before administration of the mammary cancer producing carcinogen, 7,12-dimethylbenz( $\alpha$ )anthracene (DMBA). Nevertheless most studies have been concerned with determining the mechanisms by which dietary fat enhance tumour growth they do not produce changes in cell function characteristic of diets are often referred to as 'promoters' of carcinogenesis. Hicks (1983a) has suggested 'co-carcinogen' as a more correct term for these dietary effects since although high-fat diets enhance tumour growth they do not produce changes in cell function characteristics of either stage-1 or stage- 2 promoters. Attempts to elucidate mechanisms underlying effects of high-fat diets on mammary tumorigenesis must consider the influence of both the type and amount of fat fed. Early experimental feeding studies using the carcinogen-induced model in the rat provided evidence that diets high in polyunsaturated fatty acids were more potent in enhancing tumour growth rates than high-saturated-fat diets (Carroll \& Khor, 1971). However, these studies involved comparisons of tumour incidence in animals fed on diets containing $200 \mathrm{~g}$ maize oil, beef tallow or coconut oil $/ \mathrm{kg}$; it is now recognized that the latter two diets would be virtually free of essential fatty acids (EFA). When beef tallow or coconut oil diets were supplemented with $30 \mathrm{~g}$ maize oil $/ \mathrm{kg}$ to provide EFA, tumour incidence rates were comparable in all the high-fat groups, irrespective of the type of fat fed (Hopkins \& Carroll, 1979). Ip (1987) recently found that tumour incidence was linearly related to dietary linoleate content up to a maximum level which lay between $4 \%$ and $5 \%$. Once this level was reached, the amount of fat fed was the determining factor in tumour incidence. The reason for the high dependence of mammary tumours on EFA is not known, but is also observed in transplantable tumour cells grown in culture (Kidwell et al. 1982). This dose-response effect of EFA when fed at levels less than $50 \mathrm{~g} / \mathrm{kg}$ is important in interpreting findings from feeding studies in animals in which the aim is to investigate the level of fat in the diet, since it must be ensured that the EFA content of the different diets are identical. These observations also have implications for human dietary studies and 
suggest that in future cross-cultural and case-control studies greater emphasis should be placed on measurements of dietary fatty-acid intakes and on the quantification of EFA intakes in different populations. If these studies are to be undertaken, more detailed and complete information on the fatty-acid composition of foods will be required than is available from current food composition data bases.

Further evidence that the type of fat fed may be an important determinant of mammary tumorigenesis is indicated by recent studies which show protective effects of long-chain polyunsaturated fatty acids of the $\omega 3$ class which are found in fish oils (Karmali, 1987). These protective effects operate at low dose-levels (Karmali et al. 1984) and remain even when the total fat content of the diet is high (Oza \& Karmali, 1986). Mechanisms proposed to explain effects of dietary fat on mammary tumorigenesis have been the subject of a number of reviews in recent years (Welsch, 1987), but no single mechanism adequately explains the influence of EFA content and the interactive effects of $\omega 3$ and $\omega 6$ fatty acids, as well as the influence of the amount of fat fed. The following sections consider the proposed mechanisms, details of which are mainly derived from experimental animal studies, and suggest possible lines of investigation for future studies in human populations.

\section{DIETARY FAT, ENERGY INTAKE AND MAMMARY TUMORIGENESIS}

Many feeding studies in rodents have demonstrated inhibitory effects of energy restriction on incidence and growth rates of spontaneous and carcinogen-induced tumours (Ross \& Bras, 1971). For this reason it has been argued that tumour-promoting effects of high-fat diets in both mammary (Kritschevsky et al. 1984) and colon models (Nauss et al. 1987) could be due to the energy content of high-fat diets, rather than to an effect of fat per se. In the mammary tumour model the original hypothesis for a specific effect of fat came from studies which employed isoenergetic diets with varying levels of fat. These studies showed tumour incidence and growth rates to be highest in animals fed on high-fat diets and lowest in animals fed on low amounts of fat, but equivalent amounts of energy, to the high-fat animals (Hopkins \& Carroll, 1979; Cohen et al. 1984). Ip (1987) also showed that animals fed on a high-fat energy-restricted diet, in which energy restriction was sufficiently severe to impair weight gain, still developed significantly more tumours than animals fed on a standard diet ad lib. Many studies have also reported marked differences in mammary tumour incidence in animals consuming diets of identical fat content, but varying in the type of fat fed (Hopkins et al. 1981; Chan et al. 1983). These findings strongly support the view that tumour-enhancing effects of dietary fat are mediated through the effects of specific fatty acids.

The issue of energy $v$. specific effects of dietary fat in the rodent mammary model has, however, re-emerged in the light of recent studies which report contrary findings to those outlined previously. Kritchevsky et al. (1984) found incidence and growth rates of tumours induced with DMBA to be higher in rats fed on low-fat, high-energy diets than in animals fed high-fat, energy-restricted diets. Tumour incidence rates were $67 \%$ in the low-fat, highenergy group, compared with $40 \%$ in the high-fat, energy-restricted group; the number of tumours was also reduced in the latter group. Contrary to his previous studies, Ip (1987) has also reported a $40 \%$ reduction in tumour incidence in animals fed on high-fat diets restricted to $80 \%$ of the energy intakes of animals fed on standard diets. The reasons for these conflicting findings may in part be explained by the studies of Donato \& Hegsted (1985), which suggest that, in rodents, fat is a more efficient source of energy than carbohydrate and protein. They conclude that experiments designed to investigate 
isoenergetic diets should take into account the relatively greater efficiency of utilization of dietary fat, by using net energy values for dietary components, rather than Atwater values. From their findings they suggest that a value of $48.5 \mathrm{~kJ}(11.6 \mathrm{kcal}) / \mathrm{g}$ fat may be more appropriate than the standard Atwater value of $37.6 \mathrm{~kJ}(9 \mathrm{kcal}) / \mathrm{g}$. If these values are correct then they suggest that previous studies which have employed an isoenergetic approach have applied insufficient energy restriction to the high-fat-fed animals. Boissonneault et al. (1986) have used the concept of net energy in a study of the effects of high-fat $v$. low-fat diets in the DMBA-induced mammary model in rats. They showed tumour incidence to be directly proportional to the net energy content of diets and demonstrated the lowest tumour incidence in high-fat, energy-restricted animals.

There is an emerging view that greater emphasis needs to be placed on the mechanisms by which greater energy availability can promote carcinogenesis in the mammary model. It has been argued by Kritchevsky et al. (1984) that the membrane lipid composition hypothesis, details of which are given later, does not take into account the permissive effects of increased energy. However, it is important to point out that reduced tumour incidence in high-fat energy-restricted animals has only been observed when energy restriction is sufficient to impair growth. Under these circumstances a greater proportion of dietary fat will be used for energy and less will be available to provide for specific growth-promoting effects of fatty acids at the mammary gland. The two hypotheses need not therefore be considered to be mutually exclusive. These findings from animal studies which suggest an energy effect of high-fat diets are of particular importance in the light of convincing evidence for a relationship between heavier body-weight and the incidence of human cancers. Particular consideration is given below to the reported relationship between, and mechanism of, obesity and breast cancer.

\section{BODY-WEIGHT, OBESITY AND HUMAN BREAST CANCER}

Heavier body-weight has been directly associated with cancer deaths in men and women. A large-scale study in the United States (Lew \& Garfinkel, 1979) has shown mortality rates from cancer to be elevated in individuals who were $40 \%$ or more above average weight. Colon and rectal cancers were found in excess amongst overweight men, whilst cancers of the reproductive tract, gall bladder and the breast were more commonly observed in overweight women. There is a particularly strong body of evidence to support an association between overweight and hormone-dependent cancers in women (La Vecchia $e t$ al. 1982). An impressive number of case-control studies have demonstrated a relationship between obesity and risk of breast cancer (Paffenbarger et al. 1980; Helmrich et al. 1983), although a few studies have found no association, or only a weak association, between weight and breast cancer when the analysis is corrected for height (de Waard, 1975; Soini, 1977). The relationship between body-weight and breast-cancer risk appears to operate only for cancers presenting during the post-menopausal years, since an inverse association between weight and risk of breast cancer has been demonstrated for the premenopausal disease (Paffenbarger et al. 1980; Helmrich et al. 1983). Willett et al. (1985), in a study of 120000 nurses, showed an inverse relationship between Quetelet's Index and breast-cancer risk and this asociation was strengthened when weight at age 18 years rather than current weight was considered. The mechanisms by which overweight may enhance risk of breast cancer in post-menopausal years, but provide protective effects in premenopausal years, are not known. There is, however, general agreement that effects of overweight in postmenopausal women are mediated through increased adiposity and increased capacity for peripheral synthesis of oestrogens in adipose tissue. Two recent studies have shown excessive weight gain in adult life to be associated with increased risk of post-menopausal 
breast cancer (Lubin et al. 1985; Ingram et al. 1990). Ingram et al. (1990) showed that women who gained more than $10 \mathrm{~kg}$ from early womanhood had a twofold increased risk of developing breast cancer, whilst lean women had a greater risk of being treated for benign breast disease. An effect of obesity per se rather than increased body mass is also supported by studies which show a lower prevalence of breast cancer in women athletes, who are lean and who exercise frequently. Prevalence of other hormone-dependent cancers was also shown to be lower in athletes than non-athletes (Frisch et al. 1985). Obesity appears to influence not only the incidence of breast cancer but also the progress and severity of the disease. Obese breast cancer cases have been shown to have more advanced disease on diagnosis (Rosen et al. 1977) and higher rates of recurrence and shorter survival times (Morrison et al. 1977; Donegan et al. 1978) than lean patients. It has been suggested that these variables may simply reflect a later stage of diagnosis in obese women, in whom breast lumps are more difficult to detect (Willett, 1987). Verreault et al. (1988) have recently provided evidence that more advanced disease at presentation in obese women is not simply an artefact of delayed diagnosis. This study showed that in cases with oestrogen-receptorpositive tumours, the incidence of axillary node involvement (indicating more advanced disease) was four times higher in overweight than in lean women, even after adjustments for tumour size were made. That the effect of body-weight was more marked in women with oestrogen-receptor-positive than oestrogen-receptor-negative tumours also supports the view that hormonal factors underlie effects of body-weight on breast cancer prognosis. These findings also illustrate the value of investigating nutritional influences in relation to tumour type as well as tumour site.

The mechanisms by which increased adiposity could lead to alterations in oestrogen likely to facilitate expression of breast and other hormone-dependent cancers has recently been reviewed (Herschopf \& Bradlow, 1987; Siiteri, 1987; Simpson \& Mendelson, 1987). Obese subjects have a greater capacity to synthesize oestrone from androstenedione in adipose tissue; this appears to be due to an increase in aromatase activity in adipose tissue of obese subjects. It has also been suggested that in overweight men and women oestrone metabolism is more likely to proceed through $16 \alpha$-hydroxylation pathways yielding the metabolically active oestrogen oestriol, than through $2 \alpha$-hydroxylation pathways which form inactive products of oestrogen metabolism (Siiteri, 1987). The bioavailability of oestrogen may also be increased in overweight women. Oestrogens are transported in blood bound to sex-hormone-binding globulin (SHBG) and albumin; low levels of SHBG are associated with increased free oestrogen levels and increased availability and uptake of the steroids into peripheral tissues. Overweight women have been shown to have reduced SHBG-binding capacity (Siiteri, 1987), and lower binding capacities have also been reported in breast cancer cases (Moore et al. 1982). These studies suggest that increased synthesis, reduced inactivation and increased bioavailability of oestrogens may all be expressed in overweight subjects. In post-menopausal women these effects are likely to be exacerbated due to reduced synthesis of progesterone after the menopause.

The studies outlined previously provide a plausible explanation, and a likely mechanism, for the reported association between overweight and hormone-dependent cancers in women. The evidence would also appear to support strongly the view that the effect of fat is due to increased provision of energy rather than to a specific effect of dietary fatty acids. This conclusion is supported by the findings of a recent case-control study in breast cancer in which intakes of saturated fat, animal protein and total energy were found to be higher in cases than controls (Toniolo et al. 1989). Superficially the findings might also appear to be consistent with conclusions drawn from animal studies. However, a distinction needs to be drawn between the two lines of evidence, since, in experimental animals, protective effects of energy restriction appear to operate through growth restriction, whilst in humans 
harmful effects of high-energy diets seem to be related to increased adipose tissue deposition during adult life.

In future epidemiological studies, measurements of circulating concentrations of oestrogens and their binding proteins are likely to provide useful biological markers for studying relationships between adiposity, hormones and breast cancer. A recent case-control study has demonstrated an inverse association between the body mass index (BMI) and the proportion of protein-bound oestradiol in breast cancer cases (Ingram et al. 1990), and this requires further investigation. Future studies should concentrate on measurements of adiposity as well as body-weight. Greater attention also needs to be placed on anthropometric indices of early maturation and growth rates during adolescence than has previously been the case (Micozzi, 1985).

The evidence presented previously suggests that if there is an association between dietary fat intake, endocrine status and breast cancer in human populations, then it most likely operates through increased oestrogenicity secondary to excessive body-weight. However, studies in animals have also suggested that high-fat diets might provoke elevated prolactin and oestrogen secretion directly. This evidence, and results from studies of dietary fat modification in human subjects, are discussed below.

\section{ALTERATIONS IN HORMONES IN RESPONSE TO DIETARY FAT INTAKE}

Animal studies carried out in the 1970s provided evidence that high-fat diets provoke hypersecretion of prolactin (PRL) and oestrogens (Chan et al. 1975). These studies showed that bromocriptine, which inhibits prolactin secretion, abolished differences in tumour incidence in animals fed on high- and low-fat diets. Ovariectomy, however, had no effect on differential tumour incidence in the two dietary groups, although tumour incidence was lower in both groups of ovariectomized compared with intact animals. Ip et al. (1980) also found elevated PRL concentrations in animals on a high-fat diet, although when they carried out lesioning of the hypothalamus to induce chronically high levels of PRL in both groups of animals, a higher tumour incidence was still seen in the high-fat group. This study suggested that the high-fat diet was influencing the response to, rather than the secretion of, PRL. Recent studies have failed to observe stimulatory effects of high-fat diets on PRL or oestrogen secretion in rodents (Rogers \& Westel, 1981; Aylsworth et al. 1984). Nevertheless, the dietary fat-hormone stimulation hypothesis has continued to receive attention, and has been supported by early findings obtained from dietary studies in premenopausal women, which suggested modulatory effects of the level of dietary fat on serum PRL and oestradiol concentrations (Hill et al. 1980). More recent studies have failed to demonstrate altered PRL concentrations in response to modified-fat diets, although some studies, including our own, have shown a small reduction in luteal-phase oestrogens in women transferring from a low- to a high-fat diet (Graham et al. 1982; Rose et al. 1987a; Williams et al. 1989). Conversely, a carefully controlled cross-over trial of low- and highfat diets found no difference in concentrations of pituitary hormones or ovarian steroids in women following high- and low-fat diets over a 1 -month period, although this period of study may have been too short to detect hormone changes (Hagerty et al. 1988). Shultz et al. (1987) also found no difference in oestrogens, progesterone or PRL concentrations in vegetarian and non-vegetarian women despite marked differences in consumption of fat, fibre and energy between the two groups. Recently Rose et al. (1987b) have reported elevated levels of a PRL variant (measured by bioassay) in serum of women suffering cyclical mastalgia, and showed a return to normal levels in subjects who followed a lowfat diet over a period of 3 months. Boyd et al. (1988b) have reported alleviation of symptoms 
of cyclical mastalgia in a controlled trial of a low-fat diet ( $15 \%$ energy as fat); no changes in concentrations of oestrogens, progestagens or PRL (measured by radioimmunoassay) were observed in this study. A recent carefully designed study of diets varying in both the type and level of fat fed showed that the polyunsaturated: saturated fatty-acid ratio had no influence on metabolic hormone concentrations but that the low-fat diet resulted in significantly higher insulin and significantly lower cortisol and dehydroepiandrosterone (DHEA-S) concentrations (Bhathena et al. 1989). Reproductive hormones were not measured in this study, but cortisol and DHEA-S are both derived from pregnenolone, and these findings therefore provide supportive evidence of altered steroid metabolism in premenopausal women consuming low-fat diets.

The hypothesis for direct effects of high-fat diets on mammogenic hormones (e.g. PRL and oestrogen) is not strongly supported by the current evidence available from animal and human studies. Much stronger evidence is provided from animal studies to suggest that dietary fat may influence the response to hormonal stimulation at the mammary gland itself, and that this effect may be mediated through changes in membrane fatty-acid composition (Aylsworth et al. 1981; Welsch et al. 1985; Welsch, 1986).

\section{ALTERATIONS IN MEMBRANE STRUCTURE AND FUNCTION}

Dietary fatty-acid modification produces profound changes in membrane phospholipid fatty acids in a wide range of tissues studied in both experimental animals and human subjects. Alteration in mammary membrane fatty-acid composition has therefore been proposed as a possible locus for the tumour-enhancing effects of dietary fatty acids (Williams \& Dickerson, 1987).

Increased cellular membrane fluidity has been shown to occur in response to increased membrane content of polyunsaturated fatty acids (Berlin et al. 1980), and has also been reported to be associated with increased cell division (Lai et al. 1980). Cells derived from proliferating mammary tumours have a higher linoleate content then do normal cells (Kidwell et al. 1982). It has therefore been proposed that the ability of malignant mammary cells to maintain increased membrane fluidity may be dependent on the availability of linoleate, and that this may explain the high requirement for, and growth-promoting effects of, EFA in tumour-bearing animals. However, there is as yet no direct evidence of altered membrane fluidity in tumours of animals fed on modified-fat diets. Furthermore, this hypothesis is inconsistent with the inhibitory effects of $\omega 3$ fatty acids on tumour growth since, when fed, these fatty acids become incorporated into cell membranes, where they might be expected to increase membrane fluidity and thereby enhance tumorigenesis.

Alteration in prostanoid (PG) formation, secondary to changes in the membrane content of fatty acids which act as precursors for these active compounds, provides a stronger biological basis for explaining reported effects of fatty acids on tumour formation. Recent studies have shown that indomethacin (a cyclooxygenase inhibitor) inhibits tumour formation in DMBA-treated rats fed on high-linoleate diets (Carter et al. 1983; Kollmorgen et al. 1983). PG of the series-2 (dienoic prostanoids) have been most strongly implicated, with membrane arachidonate content acting as the critical factor determining the rate of synthesis of the PG2 series of compounds (Karmali, 1987). Since arachidonic acid is formed from linoleate by a series of chain elongation and desaturation reactions, the tumourenhancing effects of dietary linoleate may be attributed to its role as an essential dietary precursor for the synthesis of membrane arachidonate. This hypothesis is also consistent with reported inhibitory effects of $\omega 3$ fatty acids on mammary tumorigenesis (Karmali et al. 1984; Oza \& Karmali, 1986) since these fatty acids are known to inhibit arachidonate metabolism. Eicosapentaenoic acid (EPA) is the precursor of the series-3 PG (trienoic PG), 
which are markedly less biologically active than their corresponding dienoic counterparts formed from arachidonate. EPA, when fed in large amounts, is known to displace arachidonate from cell membranes, and acts as a competitive inhibitor of cyclooxygenase. Thus, diets rich in EPA have been shown to reduce mammary membrane arachidonic content (Jurkowski \& Cave, 1985) and $\mathrm{PGE}_{2}$ production by mammary tumour cells (Karmali et al. 1984). These experimental findings provide a plausible explanation for effects of dietary fatty-acid modification on tumorigenesis, although the mechanisms by which PG influence cell proliferative processes are not yet fully understood. Particular attention has been placed on the dietary fat-PG hypothesis because of epidemiological evidence which shows a rising incidence of breast cancer in Greenland, Iceland and Japan, during a time when dietary habits have shifted from a high-fish, low-saturated-fat diet to one which more closely resembles the Western diet (Nielsen \& Hansen, 1980). None of the case-control studies of breast cancer published to date have studied intakes of, and the balance between, dietary $\omega 3$ and $\omega 6$ fatty acids, although it is interesting to note than in the study of Lubin et al. (1981) a high consumption of fish was associated with reduced risk of breast cancer. Human breast-cancer tissue has been repeatedly shown to produce large amounts of dienoic PG when incubated with or without arachidonic acid (Rolland et al. 1979; Bennett, 1980). However, it is not known whether PG production is a secondary consequence of malignant change or whether production of these local hormones has an aetiological role in the development of human breast tumours. Future studies which may shed light on the relevance of the PG hypothesis to the human disease could include measurements of circulating and blood cell membrane EFA concentrations, together with determinations of urinary metabolites of trienoic and dienoic PG, as well as dietary assessment of $\omega 3$ and $\omega 6$ fatty acids.

Altered PG production secondary to dietary-induced membrane fatty acid composition can be seen to provide a possible basis for the effects of dietary fat on mammary tumorigenesis. However, other membrane-associated mechanisms, and in particular the phosphoinositide signal transduction pathway, has also been identified as a possible locus for effects of dietary fat on tumorigenesis. Recognition of the role of membrane phosphoinositide hydrolysis and protein kinase activation in the initiation of cell proliferation (Nishizuka, 1984) led to the proposal that dietary-induced changes in the fatty-acid composition of membrane phosphoinositide may underlie effects of fat on mammary tumorigenesis and, in particular, may explain interactive effects of hormone and membrane changes in response to dietary fat (Williams \& Dickerson, 1987).

It is now well established that the growth of human breast cancer cells and animal mammary tumour cells is dependent on hormones and local growth-promoting factors which stimulate cell-membrane signal-transduction mechanisms (Welsch, 1985; Boyd \& Leake, 1988). Furthermore, Welsch \& Aylsworth (1983) have shown that dietary fat influences mammary growth in response to exogenous hormones; these workers also proposed that these effects may be mediated through fat-induced enhancement of the phosphoinositide signal-transduction mechanism (Welsch, 1986). Peptide hormones and growth factors are known to accelerate cell proliferation by activation of membrane phosphoinositides and consequent increases in the intracellular intermediate 1,2diacylglycerol (DAG) which activates protein kinase C. Early studies suggested that DAG containing unsaturated fatty-acid moieties was more potent than DAG enriched with saturated fatty acids in stimulating protein kinase C (Welsch, 1987). Thus, it was hypothesized that dietary-induced changes in phosphoinositide fatty-acid composition which increase the saturated fatty acid content of the phospholipid would result in formation of a less-active DAG on hormonal stimulation. However, recent studies suggest that 1,2-diacylglycerols containing saturated fatty acids are equally active as those 
containing unsaturated fatty acids in stimulating protein kinase C (Boni \& Rando, 1985; Conn et al. 1985). Our own studies have shown that, unlike the phosphatidyl choline and ethanolamine components of membrane phospholipids, the fatty-acid composition of the phosphoinositide component of mammary tissue is highly resistant to change in response to dietary fat manipulation (Williams \& Maunder, 1990). It seems unlikely therefore that this mechanism can explain enhanced tissue responsiveness to exogenous hormones, and this effect is more likely to be explained by changes in hormone-receptor affinity (Cave \& Jurkowski, 1984).

Although most studies of effects of dietary fatty acids on membrane structure and function in relation to mammary tumorigenesis have concentrated on membrane changes in the mammary gland itself, it is also conceivable that dietary effects on the membrane composition of cells of the immune system may also be of relevance. Thus, inhibitory effects of indomethacin and also $\omega 3$ fatty acids on mammary tumorigenesis may be due to altered PG production by macrophages and other cellular components of the immune response. Karmali (1987) has shown reduced $\mathrm{PGE}_{2}$ synthesis by cultured spleen lymphocytes in tissue obtained from animals fed on high- $\omega 3$-fatty acid diets, and lower tumour weights and volumes were also found in this group of animals. Hillyard \& Abraham (1979), and more recently Gabor et al. (1985), have shown higher rates of tumour-cell lysis in mice fed on low-compared with high-polyunsaturated fatty-acid diets. Reduced rates of concanavalin A-induced blastogenesis of spleen lymphocytes (Kollmorgen et al. 1979), and significantly decreased levels of peripheral blood lymphocytes (Wagner et al. 1982), have also been observed in animals fed on high-polyunsaturated fat diets. In each of the studies quoted previously, inhibitory effects of high polyunsaturated fatty acids on immune response were associated with higher rates of carcinogen-induced tumour incidence or transplantedtumour growth rates. These studies suggest that dietary fat may modulate the immune defence response to tumour cells in addition to possible direct stimulative effects of fat on tumour-cell proliferation. Alteration in immune response alone cannot explain effects of dietary fat since modulatory effects of both amount and type of fat are observed in mammary tumour cells grown in culture as well as in the intact animal (Wicha et al. 1979).

\section{COMMENT}

Evidence outlined in the preceding sections illustrates the complex interplay of factors which may underlie proposed effects of dietary fat on mammary tumorigenesis. It is hoped that results of intervention trials of low-fat diets, recently initiated in high-risk women (Boyd et al. 1988 a), and in women with existing breast cancer (Holm et al. 1990), will shed further light on the significance of dietary fat intake to the aetiology of human cancers. In the meantime, the imprecision of dietary methodologies for the assessment of fat intake in large-scale studies, and the restricted and highly variable international information available on the fatty acid composition of foods, make interpretation of information from epidemiological studies difficult to assess. These difficulties are further compounded in case-control studies by the relatively narrow distribution of both total and types of fat intake, which exist in populations in individual countries. Greater emphasis needs to be placed on detailed biochemical and hormone studies of effects of altered fat intake in preand post-menopausal women, and on the feasibility of maintaining long-term compliance with very-low-fat diets. 


\section{MICRONUTRIENTS AND CANCER}

\section{INTRODUCTION}

If, as has been suggested, cancer is caused by free radical damage, it seems reasonable to consider that micronutrients which act as antioxidants and free radical scavengers would have a protective action. Free radicals and non-radical species are continually being formec in human tissues and their safe sequestration is an important part of antioxidant defence. This defence is, in fact, composed of a mixture of naturally occurring and synthetic antioxidants which may enter the body orally from foodstuffs or through the skin from cosmetics. Antioxidants play important roles as food additives, as cellular components and as plasma constituents. Antioxidant food additives include butylated hydroxytoluene (BHT) and butylated hydroxyanisole (BHA). Naturally occurring antioxidants include phenolic compounds such as gallic and chlorogenic acids, the carotenoids, vitamins $E$ and $\mathrm{C}$ and the mineral selenium. Antioxidants present in plasma include uric acid, reduced glutathione, and enzymic antioxidants such as catalase $(E C 1.11 .1 .6)$, superoxide dismutase (EC 1.15.1.1) and glutathione peroxidase (EC 1.11.1.9).

Considering the points of attack of free radicals, antioxidants may prevent the initiation of carcinogenesis by protecting DNA from mutagenic change and the promotion and progression of the process by preventing damage to cell membranes. Because of the time interval over which these sequential changes occur there would seem to be more opportunity to intervene in the process and thus to prevent the development of cancer. Present evidence suggests that antioxidant action is a synergic process organized in a multi-layer fashion of prevention, interception and repair (Sies, 1990).

Although there has been considerable emphasis on the antioxidant role of micronutrients in cancer prevention, it is now clear that this is not the only biochemical process that may be involved. Thus, the protective role of vitamin $C$ in relation to stomach cancer may be by preventing the conversion of dietary nitrates and nitrites to the carcinogenic nitrosamines. Retinol, as distinct from $\beta$-carotene, may also act by a non-antioxidant mechanism.

Evidence for a protective role for micronutrients in man has been obtained directly from epidemiological studies in human populations and indirectly from investigations of biochemical mechanisms using synthetic carcinogens in animals or tissue culture preparations. Both these approaches have their limitations and future developments may well depend on the development of techniques which will make it possible to derive information about mechanisms of protective action from studies in human populations. 'Proof' of protective action can be obtained only from intervention studies in identifiable 'at risk' groups.

\section{EPIDEMIOLOGICAL EVIDENCE}

The strength of the evidence for a protective role for micronutrients in relation to cancer varies from one organ to another. Moreover, within a single organ it may be more evident for a particular kind of cancer. The anti-cancer activity of micronutrients is likely to be synergic rather than limited to a particular nutrient. Furthermore, the long latency period between initiation and clinical manifestation makes the evidence suggestive rather than conclusive. Presently used methods probably yield evidence of association only. Refinements in the way in which dietary information is obtained, evidence of biochemical mechanisms, together with more detailed statistical techniques, are essential if this method of investigation is to be other than descriptive. 
The following brief review illustrates the kind of evidence that has been obtained for the possible involvement of micronutrients in cancer protection in some organs.

Lung

An earlier report from Norway of a negative association between a high dietary "vitamin $A$ index' and lung cancer has been followed by the result of an 11-year follow-up of 13785 men and 2928 women (Kvale et al. 1983). The results of this study were stratified for sex, age, residence characteristics, cigarette smoking and, at times, socio-economic group. This study, like the previous one, was limited by the nature of the dietary information, but showed an apparent protection by carotene which was particularly strong for lung cancer of the squamous cell type and among those with higher alcohol intakes. Of the food items studied, carrots and milk showed the strongest negative associations.

Similar conclusions were obtained in a study of lung cancer among men in New Jersey (Ziegler et al. 1984). It is of interest, however, that the increase in relative risk (RR) was only 1.3 between the lowest and highest quintiles of carotene intake, rather lower than in the Norwegian study. Thus, it could be that evidence of a protective effect is greater in those populations in whom the spread of absolute intakes is most exaggerated. As in the Norwegian study, the link was strongest for carcinomas of the squamous cell type; no association was found between carotene intake and the development of lung adenocarcinoma, the form which predominates in non-smokers. However, in women in Los Angeles County, increased RR associated with low $\beta$-carotene intake was found with both types of lung cancer (Wu et al. 1985). More work seems necessary to show whether there is a real sex difference. Here again, though, there was no evidence of a protective effect of preformed vitamin A or of vitamin supplements.

It might be thought that prospective studies (e.g. Wald et al. 1980; Salonen et al. 1985) which showed lower serum retinol concentrations in individuals who later developed lung cancer would provide more conclusive evidence. However, these findings were not consistent with other studies which showed normal retinol concentrations in individuals who later developed lung cancer (e.g. Stähelin \& Buess, 1982). It is pertinent that plasma retinol accounts for only $1 \%$ of the body's vitamin $A$ and that plasma levels do not fall until hepatic concentrations fall below $20 \mathrm{mg} / \mathrm{g}$ (Olson, 1984). This may be one factor which accounts for the fact that even where values have been lower in cancer sufferers compared with matched controls they have not been outside the normal range.

Another factor is the cachectic nature of the disease and its possible effect on retinolbinding protein (RBP). The latter is a short-half-life protein whose concentration is reduced by protein-energy malnutrition. Malnutrition could well have accounted for the finding of a consistent relationship between low serum retinol and RBP values (Atukorala et al. 1979) and the more recent finding in a prospective study of low retinol values only in subjects who developed lung cancer within 1 year of taking the blood sample (Wald et al. 1986).

Malnutrition could be one factor accounting for the low-vitamin-C status reported in lung cancer patients (Anthony \& Schorah, 1982). However, studies of patients with cancer at other sites have suggested that vitamin- $C$ deficiency may be more important than that of $\beta$-carotene in carcinogenesis (Gey et al. 1987; Kromhout, 1987). This latter study, carried out in the Netherlands, is important because it strengthened the evidence for a role of antioxidants in the prevention of lung cancer by showing a strong inverse relationship between serum uric acid concentrations and lung-cancer mortality. It may be that the metabolic antioxidants merit further investigation. Low dietary intakes of vitamin $\mathrm{C}$ in patients who had developed lung cancer (Fontham et al. 1988) could have been due to an effect of the disease on food intake. Such a secondary effect would not account for the fact that others (Colditz et al. 1985; Marchand et al. 1989) have reported a protective effect of 
high vegetable intake which could have resulted in a high vitamin-C intake along with high $\beta$-carotene and lycopene intakes.

\section{Oral cavity and oropharynx}

From what has been said about the effect of malnutrition on plasma retinol concentrations, it might be concluded that the low plasma retinol values found in patients with oral cancer (Chaudhy et al. 1980) might be due to low food intake as a consequence of the cancer. However, similar low concentrations associated with precancerous lesions (leukoplakia) and proneness to develop cancer have been reported in betel nut and tobacco chewers (Stich et al. 1984b). In persons with these habits the occurrence of precancerous changes is reduced by $\beta$-carotene and by vitamin A supplements (Stich et al. 1984a), and it seems unlikely that these effects are caused by free-radical scavenging, and another mechanism, other than free-radical damage, seems likely to be involved with the aetiology of this type of cancer. Incidentally, low- rather than high-dose supplements seem to have the desired effect and this agrees with the greater anti-tumour effect of low-dose $(3 \mu \mathrm{g} / \mathrm{d}$ intraperitoneally) compared with high-dose $(3 \mathrm{mg} / \mathrm{d}$ intraperitoneally) retinol in experiments with a xeno-transplanted cell line (Wetherall et al. 1984).

That there may be an effect of antioxidants on some kinds of oral cancer is suggested by the finding of low erythrocyte Se values and low activity of the Se-dependent antioxidant enzyme, glutathione peroxidase, in patients with untreated cancer of the oral cavity and oropharynx (Goodwin et al. 1983).

\section{Oesophagus}

Anatomical interference with food intake occurs in many patients with cancer of the oesophagus. Thus, malnutrition might have contributed to the low plasma zinc and retinol values reported in individuals with newly diagnosed cancer at this site (Mellow et al. 1983). Whether malnutrition would also account for the low plasma Se concentrations reported in rural blacks in South Africa (Jaskiewicz et al. 1988), with their high incidence of oesophageal cancer, is not known. It is of interest that an intervention trial in China, another high-risk area for oesophageal cancer, failed to show a reduction in cancer incidence with supplements of retinol, $\mathrm{Zn}$ and riboflavin (Wahrendorf et al. 1988), though those subjects with higher plasma retinol values were more likely to have histologically normal oesophagus.

\section{Stomach}

High vitamin-C intake is associated with reduced risk of gastric cancer (Correa et al. 1985; Burr et al. 1987). However, in the latter study in South Wales there was no direct relationship between vitamin-C status and severe atrophic gastritis, a precancerous condition. The authors suggested that their findings were consistent with the hypothesis that risk of stomach cancer is determined in two stages: a long-term effect leading to atrophic gastritis which is independent of vitamin $C$, and a short-term effect in which cancer develops and in which vitamin $C$ is protective. Reference has already been made to the experimental evidence that vitamin $C$ prevents the conversion of dietary nitrate and nitrite to nitrosamines and that vitamin $C$ therefore prevents the formation of the carcinogen (Kyrtopoulos, 1987). The protective effects of fruit and vegetables could be due to their vitamin-C content, but a recent study (You et al. 1989) has shown that allium foods (onions and garlic) are also protective. It seems that the active compound could be diallyl sulphide, a major constituent of garlic oil, which in experimental animals has been shown to prevent cellular damage in the colon caused by dimethylhydrazine. Allyl methyldisulphide reduces the incidence of gastric cancers in female mice treated with the carcinogen benzo[ $\alpha]$ pyrene 
by increasing the activity of glutathione S-transferase (EC 2.5.1.18), an enzyme which is involved in the detoxification of carcinogens.

\section{Bladder}

Epidemiological studies have suggested that bladder cancer is associated with low carotenoid intake (Mettlin \& Graham, 1979) and low serum retinol, and carotenoid concentrations have been reported in Egyptians with bladder cancer (Mahmoud \& Robinson, 1982). That these low concentrations could have been due to malabsorption caused by gastrointestinal infestation by schistosomal parasites has not been excluded. In a case-control study in England, Tyler et al. (1986) found no evidence of low vitamin-A intakes or low vitamin-A status in patients with non-invasive bladder cancer. The lower status found in patients with more serious poorly differentiated invasive cancer, again, could have been caused by malnutrition. Alternatively, it could be that poor differentiation resulted from low vitamin-A status because of the role of retinoids in cell differentiation (Sporn \& Roberts, 1984).

\section{Breast}

It is noteworthy that women with breast cancer do not usually lose weight until the disease is advanced. From what has been said earlier it might be suggested that this would account, at least in part, for the finding of no evidence of low plasma retinol or $\beta$-carotene concentrations in women with breast cancer (Wald et al. 1984; Marubini et al. 1988). Wald et al. (1984) did find, however, an association between breast cancer and low plasma vitamin-E concentration. This finding may link with the breast being a fatty organ and the possible role of fat in the aetiology of breast cancer (Williams \& Dickerson, 1987).

\section{Prostate}

Prostate cancer is predominantly a disease of older men and no relationship of the disease to any dietary factor has been found in patients below 70 years of age. Above this age an increased risk has been found in men who frequently ate meat, fish, animal fats and foods containing vitamins $A$ and C (Graham et al. 1983). In another study (Paganini-Hill et al. 1987) the incidence rate increased with supplement use from $4 \cdot 77 / 1000$ for non-users of a vitamin-A supplement to $6.85 / 1000$ in those using the highest level of supplementation. A similar enhancement of risk by high vitamin and particularly high carotene intake has been reported (Kolonel et al. 1987) in five ethnic groups in Hawai. A paper from Japan (Ohno et al. 1988) reported contrasting results with lower dietary vitamin-A and $\beta$-carotene intakes associated with higher risk in older men. The authors suggested that their findings could be related to the low overall fat intake in Japan. Bosland (1988) has suggested that whilst dietary factors may have some role at each stage in the development of prostatic cancer, their strongest effect is in the change from a non-invasive to an invasive latent microcarcinoma - that is, before the clinical disease becomes evident.

Like the breast, the prostate gland is subject to hormonal influences and, as in the breast, endogenous hormones are involved in the genesis of prostate cancer (Henderson et al. 1982). Since vitamin A is involved in the synthesis of testosterone (Anonymous, 1982), it may be that high intakes of vitamin A will increase testosterone synthesis and therefore increase cancer risk.

\section{COMMENT}

Broadly speaking, two kinds of study (the relationship of diet to cancer incidence; the measurement of micronutrient status in patients and controls) have been used in man to provide evidence of the involvement of micronutrients in the aetiology of cancer. There are 
difficulties with both methods. The problem of dietary assessment has already been mentioned. The interpretation of some of the case-control studies is uncertain because of the possibility that the findings were complicated by malnutrition. For this reason, the most reliable results have probably been obtained in investigations in which concentrations of micronutrients have been raised. It is particularly interesting that in hormone-related cancers, retinoids and $\beta$-carotene may have no effect (e.g. breast cancer) or actually enhance the disease (e.g. prostate). The latter effect has obvious implications for retinoid intake in older men.

\section{EXPERIMENTAL EVIDENCE}

The kind of investigation that can be carried out in human subjects is severely limited and it may never be possible to elucidate the mechanism of action of micronutrients in carcinogenesis in man. Animal models have been used for studies at three levels of organization: the whole animal, the whole organ, and at the molecular level (Sporn \& Roberts, 1984). Chemical carcinogens have been used to induce tumours in a variety of species, but principally in hamsters, rats and mice. Of the micronutrients, retinoids have attracted most attention, since carcinomas, tumours of epithelial tissues, account for about $95 \%$ of fatal malignancies in man. Retinol itself is toxic in high doses because it is avidly taken up by the liver with consequent destruction of parenchymal cells. For this reason a large number of synthetic retinoids have been produced which, whilst possessing vitaminA like activity, have lower hepatic toxicity. The role of retinoids in carcinogenesis has been reviewed elsewhere (Hicks, $1983 b$; Sporn \& Roberts, 1984) and the US National Cancer Institute has published a collection of 511 abstracts of papers dealing with retinoids, $\beta$ carotene and cancer (Moon, 1986). Antioxidants can be both chemo-preventive and carcinogenic and these properties have been reviewed by Ito \& Hirose (1989). For these reasons only a few papers will be reviewed here to illustrate possible relationships of micronutrients in experimental tumorigenesis.

\section{Initiation and/or promotion}

Administration of retinol with the carcinogen 3-methylchloranthrene significantly reduces the incidence and development of squamous-cell carcinomas in mice and basal-cell carcinomas in rats (Lupulescu, 1984) by reducing DNA synthesis and inhibiting neoplastic cell proliferation (Gensler \& Bowden, 1984). On the basis of their study on the influence of 13-cis-retinoic acid on mouse-skin tumour initiation with benzo[ $\alpha]$ pyrene and $N$-methyl$N^{\prime}$-nitro- $N$-nitrosoguanidine, Gensler \& Bowden (1984) suggested that the action of retinoids in preventing tumour initiation or promotion was carcinogen- or procarcinogenspecific. But chemical carcinogens are also organ- or tissue-specific, and other work (Fischer et al. 1985) has shown that retinoic acid can act as a weak first-stage promoter or complete promoter for skin carcinogenesis in the Sencar mouse. The authors suggested that this effect may be due to oxidative reactions at the cell membrane. It is of interest therefore that they also found the retinoic acid could prevent promotion of tumours by $12-O$ tetradecanoylphorbol-13-acetate (TPA).

\section{Differentiation}

Vitamin A is essential for the normal differentiation of epithelial tissues throughout the body (Wolbach \& Howe, 1925). Absence of normal amounts of the vitamin prevents normal differentiation and results in hyperplasia and keratinization. The hyperplasia is reversible when normal levels of vitamin A are restored. Metaplasia is a precancerous condition and the first observation that this could be replaced by normal tissues seems to have been reported by Lasnitski (1955). The premalignant phenotype of mouse prostate 
gland treated in organ cultures with 3-methylcholanthrene was altered by retinoids. The atypical epithelial cells induced by the carcinogen were replaced by normally differentiated tubules. The fact that the preparation used in this study was prostate gland does not mean that it has relevance to human prostate cancer, for the latter, as previously discussed, is hormone-dependent and not, as far as we know, caused by chemical carcinogens of the type used experimentally. However, work by Sporn et al. (1976) has supported the view that the anti-cancer properties of vitamin $\mathbf{A}$ are due to a reinforcement of normal phenotype expression with consequent repression of the malignant phenotype. Retinoids therefore act not as antioxidants but as steroid hormones, preventing promotion of cancer.

Similar prevention of phenotype expression by a retinoid (retinoic acid) has also been reported from tissue culture studies with several human neuroblastoma lines (Siddell et al. 1983). Alterations included morphological differentiation with the formation of neurite extensions in four cell lines. This effect of retinoic acid is associated with the presence in the cytosol of specific cellular retinoic acid-binding protein (CRABP), a receptor-like protein implicated in the molecular functioning of vitamin $A$. Work on the anti-cancer action of the carotenes has focused heavily on $\beta$-carotene because of its antioxidant properties. Another carotene, $\alpha$-carotene, has been reported (Murakoshi et al. 1989) to have an inhibitory effect on the growth of human neuroblastoma cells which is 1.5 times greater than that of $\beta$-carotene. $\alpha$-Carotene caused suppression of $N$-mycin messenger RNA of the tumour cells and the cells were arrested at the Go-Gi phase of their cell cycle. Thus, $\alpha-$ carotene appears to have an effect on tumours which is distinct from that of retinoic acid. This study suggests that carotenes other than $\beta$-carotene should be studied. Further evidence supporting the need for closer investigation of these compounds has been provided by Ben-Amotz et al. (1989). These workers have reported that natural isomer mixtures of $\beta$-carotene may differ in their bioavailability in rats and chicks from that of synthetic cell-trans- $\beta$-carotene. This study suggests that more attention than hitherto needs to be given to the source of $\beta$-carotene preparations used in anti-cancer studies.

\section{Latency}

There is convincing information that a number of different retinoids prevent chemical carcinogenesis in skin, mammary gland and bladder in experimental animals. However, such experiments are usually of comparatively short duration and Hicks (1983 $b$ ) has provided evidence from studies of retinoids in rats treated with the bladder carcinogen $N$ butyl- $N$-(4-hydroxybutyl) nitrosamine that the effects of retinoids in rodents could be explained in terms of a lengthening of the latent period before the tumour starts its exponential growth. In terms of potential usefulness in cancer prevention in humans, a lengthening of the latent period might still be useful, for many cancers occur in older people.

If micronutrients are to have any practical place in the prevention of cancer it seems necessary to know about another kind of latency, that of the timing of ingestion of nutrients in relation to the initial DNA damage. This matter has been studied in female rats given DMBA (Seifter et al. 1984). Supplemental $\beta$-carotene given 5 weeks after, or $30 \mathrm{~d}$ before, DMBA treatment protected against tumorigenesis. It is not clear if this kind of preventive action is restricted to $\beta$-carotene or if it extends to retinoids. This could be a critical aspect of the practical value of their protective role.

\section{Antioxidants}

It seems possible that the anti-tumour action of $\beta$-carotene in DMBA-treated rats was due to its antioxidant properties. This suggestion is strengthened by the finding (Horvath \& Ip, 1983) that Se also reduced tumour incidence in DMBA-treated animals. However, 
another antioxidant, vitamin $\mathrm{E}$, had no effects on its own, though it did enhance the effect of Se. The authors could find no evidence that the effect of Se was due to an enhancement of the activity of the Se-containing enzyme, glutathione peroxidase. They suggested that vitamin $\mathrm{E}$ might be able, by some mechanism, to provide a more favourable climate against chemical stress, thereby potentiating the action of Se.

\section{Interrelationships with hormones}

Many human mammary tumours are hormone-sensitive and patients with breast cancer may be treated with an oestrogen inhibitor, tamoxifen. Welsch et al. (1984) studied the effects of retinoid- (retinyl-acetate) feeding and tamoxifen on the progression of $N$-methyl$N$-nitrosourea-induced mammary carcinoma in the rat. Treatment started $3-10 \mathrm{~d}$ after receiving the carcinogen. At 1 year, treatment with either retinyl acetate or tamoxifen had significantly reduced mammary cancer incidence, but a greater reduction was found in animals given a combination of these substances. Further evidence of interaction of retinyl acetate with hormones was the finding that the retinoid suppressed the cancer-inducing effect of hyperprolactinaemia by blocking the stimulatory effect of PRL on mammarygland DNA.

\section{Other aspects}

Iodine deficiency or goitre may play a role in human thyroid cancer (McTieman et al. 1984) and dietary deficiency is a potent promoter of thyroid cancer in male rats treated with an initiating dose of $N$-methylnitrosourea (MNU). I deficiency alone is tumorigenic. After 77 weeks on such a diet male rats showed thyroid follicular adenomas (60\% incidence) and follicular carcinomas (10\% incidence) (Oshima \& Ward, 1986). In conjunction with MNU the I-deficient diet reduces the latency period. The mechanism of the weak carcinogenic action of the I-deficient diet is not known.

\section{COMMENT}

A number of chemical carcinogens have been used to produce tumours in different organs and tissues in experimental animals. Using these substances in conjunction with micronutrients has provided evidence of tumour-preventive properties at different stages of carcinogenesis. Moreover, different biochemical mechanisms have been shown to be involved, for whilst antioxidants may protect by free-radical scavenging, retinol seems to act by another mechanism and vitamin $\mathrm{C}$ by virtue of its reducing properties preventing the in vivo formation of a carcinogen. It seems unlikely that the various micronutrients work independently, as they have been tested in experimental animals, but rather that they act synergically. It also seems unlikely that their action is independent of energy metabolism, or cellular proteins and the complex lipids of membranes. These interactions for the most part await further elucidation, possibly using new techniques involving markers of DNA damage and connective tissue breakdown which will make it possible to follow longitudinally the metabolic changes associated with carcinogenesis.

\section{CONCLUSIONS}

There are encouraging indications that dietary modifications together with appropriate supplements of key micronutrients may prevent some forms of cancer. However, the picture is complex, with the involvement of nutritional factors varying from one kind of cancer to another. The fact that cancers develop in stages with consequent lapse of time 
between initiation and clinical manifestation means that the time during which nutrients can interfere with the process may be considerable. The crucial studies to establish the practical value of nutrition in the prevention of cancer are those involving intervention: changing the nutrition of an 'at risk' population and monitoring its effects. Several studies of this kind are in progress but their successful execution poses considerable problems.

Breast cancer occurs in about one in seventeen women in the UK. Testing the possible relationship of fat intake to the development of breast cancer would seem to be a matter of urgency. A number of factors are known to increase the risk of developing breast cancer, including having a parent with the disease. Devising a low-fat diet would seem to be easy, but what level of fat is required to produce the desired effect, and will a diet containing this amount be acceptable over a long period by a symptomatic woman? Unsatisfactory compliance in the acceptance of low-fat diets in studies on coronary heart disease (MRFIT Research Group, 1982) are a warning that lack of compliance may seriously compromise such studies. Short-term studies are needed to establish if the effects of dietary fat on hormone secretion are genetically controlled.

Intervention studies with micronutrients administered in capsule or tablet form do not present the problems encountered with a major dietary component. Nevertheless, experience with drug trials again raises the question of compliance. In drug trials there is often a considerable placebo effect. Will such an effect occur with nutritional supplements in the prevention of cancer?

\section{REFERENCES}

Ames, B. N. (1979). Identifying environmental chemicals causing mutation and cancer. Science 204, $587-594$.

Anonymous (1982). The function of retinol and retinoic acid in the testes. Nutrition Reviews 40, $187 \cdot 189$.

Anthony, H. M. \& Schorah, C. J. (1982). Severe hypovitaminosis C in lung-cancer patients. British Journal of Cancer 46, 354-367.

Armstrong, B. \& Doll, R. (1975). Environmental factors and cancer incidence and mortality in different countries, with special reference to dietary practices. International Journal of Cancer 15, 617-631

Atukorala, S., Basu, T. K., Dickerson, J. W. T., Donaldson, D. \& Sakula, A. (1979). Vitamin A, zinc and lung cancer. British Journal of Cancer 40, 927-931.

Aylsworth, C. F., Van Vugt, D. A., Sylvester, P. W. \& Meites, J. (1981). A direct mechanism by which high fat diets stimulate mammary tumor development. Proceedings of the American Association for Cancer Research (AACR) ASCO 22, 12.

Aylsworth, C. F., Van Vugt, D. A., Sylvester, P. W. \& Meites, J. (1984). Failure of high dietary fat to influence serum prolactin levels during the estrous cycle in female Sprague-Dawley rats. Proceedings of the Society for Experimental Biology and Medicine 175, 25-29.

Becker, F. (1975). Cancer: A Comprehenive Treatise. New York: Plenum Press.

Ben-Amotz, A., Mokady, S., Edelstein, S. \& Avron, M. (1989). Bioavailability of a natural isomer mixture as compared with synthetic cell-trans- $\beta$-carotene in rats and chicks. Journal of Nutrition 119, $1012-1019$.

Bennett, A. (1980). Prostaglandins and their synthesis inhibitors in cancer. In Hormones and Cancer, pp. 515-516 [S. Iacobelli, editor]. New York: Raven Press.

Berlin, E., Matusik, E. J. \& Young, C. (1980). Effect of dietary fat on the fluidity of platelet membranes. Lipids $15,604-608$.

Berrino, F. \& Muti, P. (1989). Mediterranean diet and cancer. European Journal of Clinical Nutrition 43, Suppl. $2,49-55$.

Bhathena, S. J., Berlin, E. B., Judd, J., Nair, P. P., Kennedy, B. W., Jones, J., Smith, P. M., Jones, Y., Taylor, P. R. \& Cambell, W. S. (1989). Hormones regulating lipid and carbohydrate metabolism in premenopausal women: modulation by dietary lipids. American Journal of Clinical Nutrition 49, 752-757.

Boissonneault, G. A., Elson, C. E. \& Pariza, M. W. (1986). Net energy effects of dietary fat on chemically induced mammary carcinogenesis in F344 rats. Journal of the National Cancer Institute 76, 335-338.

Boni, L. T. \& Rando, R. R. (1985). The nature of protein kinase C activation by physically defined phospholipid residues and diacylglycerols. Journal of Biological Chemistry 260, 10,819-10,825.

Bosland, M. (1988). The etiopathogenesis of prostatic cancer with special reference to environmental factors. Advances in Cancer Research 51, 1-106.

Boyd, N. F., Cousins, M., Beaton, M., Fishell, E., Wright, B., Fish, E., Kriukov, V., Lockwood, G., Tritchler, D., Wedad, H. \& Page, D. L. (1988a). Clinical trial of low-fat high carbohydrate diet in subjects with mammographic dysplasia : report of early outcomes. Journal of the National Cancer Institute 80, 1244-1248. 
Boyd, N. F., Shannon, P., Driukov, V., Fish, E., Lockwood, G., McGuire, V., Cousins, M., Mahoney, L., Lickley, L. \& Tritchler, D. (1988b). Effect of a low-fat high-carbohydrate diet on symptoms of cyclical mastopathy. Lancet ii, 128-132.

Boyd, P. \& Leake, R. (1988). Progress in understanding breast cancer : epidemiological and biological interactions. Breast Cancer Research and Treatment 11, 91-112.

Burr, M. L., Samloff, I. M., Bates, C. J. \& Holliday, R. M. (1987). Atrophic gastritis and vitamin C status in two towns with different stomach cancer deaths. British Journal of Cancer 56, 163-167.

Byers, T. (1988). Diet and cancer. Any progress in the interim? Cancer 62, 1713-1724.

Carroll, K. K. \& Khor, H. T. (1971). Effects of level and type of dietary fat on incidence of mammary tumors induced in female Sprague-Dawley rats by 7,12-dimethylbenz( $\alpha$ )anthracene. Lipids 6, 415-420.

Carter, C. A., Milholland, R. J., Shea, W. \& Ip, M. M. (1983). Effect of prostaglandin synthetase inhibitor indomethacin on 7,12-dimethylbenz( $\alpha$ )anthracene-induced mammary tumorigenesis in rats fed different levels of fat. Cancer Research 43, 3559-3562.

Cave, W. T. \& Jurkowski, J. J. (1984). Dietary lipid effects on the growth, membrane composition and prolactinbinding capacity of rat mammary tumors. Journal of the National Cancer Institute 73, 185-191.

Chan, P., Didato, F. \& Cohen, L. A. (1975). High dietary fat, elevation of rat serum prolactin and mammary cancer. Proceedings of the Society of Experimental Biology and Medicine 149, 133-135.

Chan, P. C., Ferguson, K. A. \& Dao, T. L. (1983). Effects of different dietary fats on mammary carcinogenesis Cancer Research 43, 1079-1083.

Chaudhy, N. A., Jafarey, N. A. \& Ibrahim, K. (1980). Plasma vitamin A and carotene levels in relation to the clinical stage of carcinoma of the oral cavity and oropharynx. Journal of the Pakistan Medical Association 30 , 221-223.

Chilvers, C., Fraser, P. \& Beral, V. (1979). Alcohol and oesophageal cancer: an assessment of the evidence from routinely collected data. Journal of Epidemiology and Community Health 33, 127-133.

Cohen, L. A., Thompson, D. O., Maeura, Y. \& Weisburger, J. H. (1984). Influence of dietary medium-chain triglycerides on the development of $N$-methylnitrosourea-induced rat mammary tumors. Cancer Research 44 , 5023-5028.

Colditz, G. A., Branch, L. G., Lipnick, R. J., Willett, W. C., Rosner, B., Bosner, B. M. \& Hennekens, C. H. (1985). Increased green and red vegetable intake and hormonal cancer deaths in an elderly population. American Journal of Clinical Nutrition 41, 32-36.

Committee on Diet, Nutrition and Cancer (1982). Assembly of Life Sciences, National Research Council. Diet, Nutrition and Cancer, pp. 1-16. Washington, DC: National Academy Press.

Conn, P. M., Gangong, B. R., Ebeling, J., Staley, D., Neidel, J. E. \& Bell, R. M. (1985). Diacylglycerols release LH: structure-activity relations reveal a role for protein kinase C. Biochemical and Biophysical Research Communications 126, 532-539.

Correa, P. (1981). Nutrition and cancer: epidemiologic correlations. In The Practice of Cancer Prevention in Clinical Medicine, pp. 1-10 [G. R. Newell, editor]. New York: Raven Press.

Correa, P., Fontham, E., Pickle, L. W., Chen, V., Lin, Y. \& Haenslel, W. (1985). Dietary determinants of gastric cancer in South Louisiana. Journal of the National Cancer Institute 75, 645-653.

Dao, T. L. \& Chan, P. C. (1983). Effect of duration of rat intake on enhancement of mammary carcinogenesis in rats. Journal of the National Cancer Institute 71, 201-205.

Doll, R. \& Peto, R. (1981). The causes of cancer: quantitative estimates of avoidable risks of cancer in the United States today. Journal of the National Cancer Institute 66, 11911308.

Donato, K. \& Hegsted, D. M. (1985). Efficiency of utilisation of various sources of energy for growth. Proceedings of the National Academy of Sciences USA 82, 48664870.

Donegan, W. L., Hartz, A. J. \& Rimm, A. A. (1978). The association of body weight with recurrent cancer of the breast. Cancer 41, 15901594.

Emerit, I., Levy, A. \& Cerutti, L. (1983). Suppression of tumor promoter phorbomyrisate acetate-induced chromosome breakage by antioxidants and inhibitors of arachidonic acid metabolism. Mutation Research 110 , 327-335.

Fischer, S. M., Klein-Szanto, A. J., Adams, L. M. \& Slaga, T. J. (1985). The first stage and complete promoting activity of retinoic acid but not the Analog RO-10-9359. Carcinogenesis 6, 575-578.

Fontham, E. T. H., Pickle, L. W., Haenszel, W., Correa, P., Lin, Y. \& Falk, R. T. (1988). Dietary vitamins A and $\mathrm{C}$ and lung cancer risk in Louisiana. Cancer 62, 2267-2273.

Freudenheim, Jo. L. \& Marshall, J. R. (1988). The problem of profound mismeasurement and the power of epidemiological studies of diet and cancer. Nutrition and Cancer 11, 243-250.

Frisch, R. E., Wyshak, G. \& Albright, N. L. (1985). Lower prevalence of breast cancer and cancers of the reproductive system among former college athletes compared to non-athletes. British Journal of Cancer $\mathbf{5 2}$, $885-891$

Funes, J., Yong, S. \& Karel, M. (1980). Changes in lysozyme due to reactions with volatile products of peroxidizing methyl linoleate. Journal of Agricultural and Food Chemistry 28, 794-798.

Gabor, H., Hillyard, L. A. \& Abraham, S. (1985). Effect of dietary fat on growth kinetics of transplantable mammary adenocarcinoma in Balb/C mice. Journal of the National Cancer Institute 74, 1299-1305. 
Gensler, H. \& Bowden, G. T. (1984). Influence of 13-cis-retinoic acid on mouse skin tumor initiation and promotion. Cancer Letters 22, 71-75.

Gey, K. F., Brubacher, G. B. \& Stähelin, H. B. (1987). Plasma levels of antioxidant vitamins in relation to chronic heart disease and cancer. American Journal of Clinical Nutrition 45, 1368-1377.

Goodwin, W. J., Lane, H. W., Bradford, K., Marshall, M. V., Griffin, A. C., Geopfert, H. \& Jesse, R. H. (1983). Selenium and glutathione peroxidase levels in patients with epidermoid carcinoma of the oral cavity and oropharynx. Cancer 51, 110-115.

Graham, S., Haughey, B., Marshall, J., Priore, R., Byers, T., Rzepka, T., Mettlin, C. \& Pontes, J. E. (1983). Diet in the epidemiology of carcinoma of the prostate gland. Journal National Cancer Institute 70, 786-692.

Graham, S., Marshall, J., Mettlin, C., Rzepka, T., Memto, T. \& Byers, T. (1982). Diet in the epidemiology of breast cancer. American Journal of Epidemiology 116, 68-75.

Hagerty, M. A., Howie, B. J., Tan, S. \& Shultz, T. D. (1988). Effect of low and high-fat intakes on the hormonal milieu of premenopausal women. American Journal of Clinical Nutrition 48, 653-659.

Helmrich, S. P., Shapiro, S. \& Rosenberg, L. (1983). Risk factors for breast cancer. American Journal of Epidemiology 115, 241-245.

Henderson, B. E., Ross, R. K., Pike, M. C. \& Casagrande, J. T. (1982). Endogenous hormones as a major factor in human cancer. Cancer Research 42, 3232-3239.

Herschopf, R. J. \& Bradlow, H. L. (1987). Obesity, diet, endogenous estrogens, and the risk of hormone-sensitive cancer. American Journal of Clinical Nutrition 45, 283289.

Hicks, R. M. (1983a). Pathological and biochemical aspects of tumor promotion. Carcinogenesis 4, $1209-1214$.

Hicks, R. M. (1983 b). The scientific basis for regarding vitamin A and its analogues as anticarcinogenic agents. Proceedings of the Nutrition Society 42, 83-101.

Hill, M. J. (1989). Experimental studies of fat, fibre and calories in carcinogeneses. In Diet and the Aetiology of Cancer. European School of Oncology Monographs, pp. 31-38 [A. B. Miller, editor]. Heidelberg: SpringerVerlag.

Hill, P., Garbaczewski, L., Helman, P., Huskission, J., Sporangisa, E. \& Wynder, E. L. (1980). Diet, lifestyle and menstrual activity. American Journal of Clinical Nutrition 33, 11,982 11,988.

Hillyard, L. A. \& Abraham, S. (1979). Effect of dietary polyunsaturated fatty acids on growth of mammary adenocarcinoma in mice and rats. Cancer Research 39, 4430-4437.

Holm, L. E., Nordevang, E., Ikkala, E., Hallström, L. \& Callmer, E. (1990). Dietary intervention as adjuvant therapy in breast cancer patients: a feasibility study. Breast Cancer Research. (In the Press.)

Hopkins, G. J. \& Carroll, K. K. (1979). Relationship between amount and type of dietary fat in promotion of mammary carcinogenesis induced by 7,12-dimethylbenz( $\alpha$ )anthracene. Journal of the National Cancer Institute 62, $1009-1012$.

Hopkins, G. J., Kennedy, T. G. \& Carroll, K. K. (1981). Polyunsaturated fatty acids as promoters of mammary carcinogenesis induced in Sprague-Dawley rats by 7,12-dimethylbenzanthracene. Journal of the National Cancer Institute 66, 517-522.

Horvath, P. M. \& Ip, C. (1983). Synergistic effect of vitamin E and selenium in the chemoprevention of mammary carcinogenesis in rats. Cancer Research 43, 5335-5341.

Ingram, D., Nottage, E., Ng, S., Sparrow, L., Roberts, A. \& Willcox, D. (1990). Obesity and breast disease: The role of the female sex hormones. Cancer (In the Press.)

Ip, C. (1987). Fat and essential fatty acid in mammary carcinogenesis. American Journal of Clinical Nutrition 45 , $218-224$.

Ip, C., Yip, P. \& Bernadis, L. L. (1980). Role of prolactin in the promotion of diemthylbenzanthracene-induced mammary tumors by dietary fat. Cancer Research 40, 374-378.

Ito, N. \& Hirose, M. (1989). Antioxidants - carcinogenic and chemo-preventive properties. Advances in Cancer Research 53, 247-302.

Jaskiewicz, K., Marasas, W. F. O., Rossouw, J. E., van Niekerk, F. E. \& Heine, E. W. P. (1988). Selenium and other mineral elements in population at risk of esophageal cancer. Cancer 62, 2635-2639.

Jurkowski, J. J. \& Cave, W. T. (1985). Dietary effects of menhaden oil on the growth and membrane lipid composition of rat mammary tumors. Journal of the National Cancer Institute 74, 1145-1150.

Karmali, R. A. (1987). Fatty acids: inhibition. American Journal of Clinical Nutrition 45, $225-229$

Karmali, R. A., Marsh, J. \& Fuchs, C. (1984). Effects of $\omega 3$ fatty acids on the growth of a rat mammary tumor. Journal of the National Cancer Institute 73, 457461.

Kidwell, W. R., Knazeck, R. A., Vonderhaar, B. K. \& Lasonczy, I. (1982). Effects of unsaturated fatty acids on the development and proliferation of normal and neoplastic breast epithelium. In Molecular Interactions of Nutrition and Cancer, pp. 219-226 [M. S. Amott, J. van Eyes and Y. Yang, editors]. New York: Raven Press.

Kollmorgen, G. M., King, M. M.. Kosanke, D. \& Do, C. (1983). Influence of dietary fat and indomethacin on the growth of transplantable mammary tumors in rats. Cancer Research 43, 4714-4719.

Kollmorgen, G. M., Sansing, W. A., Lehman, A. A., Fischer, G., Longley, R. E., Alexander, S. S., King, M. M. \& McCay, P. B. (1979). Institution of lymphocyte function in rats fed high-fat diets. Cancer Research 39, 3458-3462. 
Kolonel, L. N., Hankin, J. H. \& Yoshizawa, C. N. (1987). Vitamin A and prostate cancer risk in elderly men: enhancement of risk. Cancer Research 47, 2982-2985.

Kritchevskey, D., Weber, M. M. \& Klurfield, D. M. (1984). Dietary fat versus calorie content in initiation and promotion of 7,12-dimethylbenz $(\alpha)$ anthracene in mammary tumorigenesis in rats. Cancer Research 44, 3174-3177.

Kromhout, D. (1987). Essential micronutrients in relation to carcinogenesis. American Journal of Clinical Nutrition 45, $1361-1367$.

Kvale, G., Bjelke, E. \& Gart, J. J. (1983). Dietary habits and lung cancer risk. International Journal of Cancer 31 , $397-405$.

Kyrtopoulos, S. A. (1987). Ascorbic acid and the formation of $N$-nitroso compounds: possible role of ascorbic acid in cancer prevention. American Journal of Clinical Nutrition 45, $1344-1350$.

La Vecchia, C., Franceschi, S. \& Gallus, G. (1982). Prognostic features of endometrial cancer in oestrogen users and obese women. American Journal of Obstetrics and Gynecology 144, 387-390.

Lai, C. S., Hopwood, L. E. \& Swartz, H. M. (1980). Electron spin resonance studies of changes in membrane fluidity of Chinese hamster ovary cells during the cell cycle. Biochimica \& Biphysica Acta 602, 117-126.

Lasnitski, 1. (1955). The influence of A hypervitaminosis on the effect of 20 methylcholanthrene on mouse prostate glands grown in vitro. British Journal of Cancer 9, 434-441.

Lew, E. A. \& Garfinkel, L. (1979). Variations in mortality by weight among 750,000 men and women. Journal of Chronic Diseases 32, $563-576$.

Louis, C. J. (1978). Tumours: Basic Principles and Clinical Aspects. Edinburgh: Churchill Livingstone.

Lubin, F., Ruder, A. M., Wax, Y. \& Modan, B. (1985). Overweight and changes in weight throughout adult life in breast cancer aetiology. American Journal of Epidemiology 122, $579-588$.

Lubin, J. H., Burns, P. E., Blot, W. J., Ziegler, R. G., Lees, A. W. \& Fraumeni, J. F. (1981). Dietary factors and breast cancer risk. International Journal of Cancer 28, 685-691.

Lupulescu, A. P. (1984). Inhibition of DNA synthesis and cell proliferation in carcinomas by vitamin A (retinol). Journal of Cell Biology $99,151 \mathrm{a}$.

McTieman, A. M., Weiss, N. S. \& Daling, J. R. (1984). Incidence of thyroid cancer in women in relation to previous exposure to radiation therapy and history of thyroid disease. Journal of the National Cancer Institute 73, 575-581.

Mahmoud, L. A. N. \& Robinson, W. A. (1982). Vitamin A levels in human bladder cancer. International Journal of Cancer 30, 143-145.

Marchand, L. Le., Yoshizawa, C. N., Kolonel, L. N., Hankin, J. H. \& Goodman, M. T. (1989). Vegetable consumption and lung cancer risk: A population-based case-control study in Hawaii. Journal of National Cancer Institute 81, 11581164.

Marubini, E., Decarli, A., Costa, A., Mazzoleni, C., Andreoli, C., Barbieri, A., Capitelli, E., Carlucci, M., Cavallo, F., Monferroni, N., Pastorini, U. \& Salvini, S. (1988). The relationship of dietary intake and serum levels of retinol and $\beta$-carotene with breast cancer. Results of a case-control study. Cancer 61, $173-180$.

Marx, J. L. (1983). Do tumor promoters affect DNA after all? Science 219, 158-159.

Mellow, M. H., Layne, E. A., Lipman, T. O., Kaushik, M., Hostetler, C. \& Smith, J. C. (1983). Plasma zinc and vitamin $\mathrm{A}$ in human squamous carcinoma of the esophagus. Cancer 51, 1615-1620.

Mettlin, C. \& Graham, S. (1979). Dietary risk factors in human bladder cancer. American Journal of Epidemiology 110, 255-263.

Micozzi, M. S. (1985). Nutrition, body size and breast cancer. Yearbook of Physical Anthropology 28, 175-206.

Miller, A. B. (1985). Diet, nutrition and cancer: an epidemiological overview. Journal of Nutrition, Growth and Cancer 2, 159-171.

Moon, R. C. (1986). Selected Abstracts on Retinoids, $\beta$-Carotene and Cancer. R. A. Block International Cancer Information Center, Bethesda, USA: National Cancer Institute.

Moore, J. W., Clarke, G. M. G., Bulbrook, R. D., Hayward, J. L., Hammond, G. L. \& Siiteri, P. K. (1982). Serum concentrations of total and non protein bound oestradiol in patients with breast cancer and in normal controls. International Journal of Cancer 29, 17-21.

Morrison, A. S., Lowe, C. R. \& MacMahon, B. (1977). Incidence risk factors and survival in breast cancer: report on five years of follow-up observation. European Journal of Cancer 13, 209-214.

MRFIT Research Groups (1982). Multiple Risk Factor Intervention Trial. Risk factor changes and mortality results. Journal of the American Medical Association 248, 1465-1477.

Murakoshi, M., Takayasu, J., Kimura, O., Kohmura, E., Nishino, H., Iwashima, A., Okuzumi, J., Sakai, T., Sugimoto, T., Imanishi, J. \& Iwasaki, R. (1989). Inhibitor effects of $\alpha$-carotene on proliferation of the human neuroblastoma cell line GOTO. Journal of National Cancer Institute 81, 1649-1652.

Nauss, K. M., Jacohs, L. R. \& Newberne, P. M. (1987). Dietary fat and fiber : relationship to calorie intake body growth and colon tumorigenesis. American Journal of Clinical Nutrition 45, 243251.

Nielsen, N. H. \& Hansen, J. P. H. (1980). Breast cancer in Greenland: selected epidemiological clinical and histological features. Journal of Cancer Research and Clinical Oncology 98, 287 -299.

Nishizuka, Y. (1984). Turnover of inositol phospholipids and signal transduction. Science 225, 13651370. 
Ohno, Y., Yoshida, O., Oishi, K., Okada, K., Yamabe, H. \& Schroeder, F. H. (1988). Dietary $\beta$-carotene and cancer of the prostate: a case-control study. Cancer 48, 1331-1336.

Ohuchi, K. \& Levine, L. (1980). $\alpha$-Tocopherol inhibits 12-0-tetradecanoyl-phorbol-13-acetate-stimulated deacylation of cellular lipids, prostaglandin production, and changes in cell morphology of Modin-Darby canine kidney cells. Biochimica et Biophysica Acta 619, 11-19.

Oshima, M. \& Ward, J. M. (1986). Dietary idodine deficiency as a tumor promoter and carcinogen in male F344/NCr rats. Cancer Research 46, 877-883.

Olson, J. A. (1984). Serum levels of vitamin A and carotenoids as reflectors of nutritional status. Journal of the National Cancer Institute 73, 1439-1444.

Oza, R. P. \& Karmali, R. A. (1986). Dietary effects of $\omega-3$ fatty acids on the growth of R3230AC mammary tumor. Federation Proceedings 45, 1089 Abstr.

Paffenbarger, R. S. Jr, Kampert, J. B. \& Chang, H. G. (1980). Characteristics that predict risk of breast cancer before and after the menopause. American Journal of Epidemiology 112, 163-168.

Paganini-Hill, A., Chao, A., Ross, R. K. \& Henderson, B. E. (1987). Vitamin A, $\beta$-carotene, and the risk of cancer: a prospective study. Journal of the National Cancer Institute 79, 443-448.

Peto, R., Doll, R., Buckley, J. D. \& Sporn, M. B. (1981). Can dietary $\beta$-carotene materially reduce human cancer rates? Nature 290, 201-208.

Poirier, L. A. (1987). Stages in carcinogenesis: alteration by diet. American Journal of Clinical Nutrition 45 , 185-191.

Rogers, A. E. \& Westel, W. C. (1981). Mammary carcinogenesis in rats fed different amounts and types of fat. Cancer Research 41, $3735-3737$.

Rolland, P. H., Maretin, P. M., Rolland, A. M., Bourry, M. \& Serment, H. (1979). Benign breast disease: studies of prostaglandin E2, steroids and the thermographic effects of inhibitors of prostaglandin biosynthesis. Obstetrics and Gynecology 54, 715-719.

Rose, D. P., Boyar, A. P., Cohen, C. \& Strong, L. E. (1987a). Effect of a low-fat diet on serum hormone levels in women with cystic breast disease. II. Serum steroids and gonadotrophins. Journal of the National Cancer Institute 78, 623-626.

Rose, D. P., Cohen, L. A., Berke, B. \& Strong, L. E. (1987b). Effect of a low-fat diet on serum hormone levels in women with cystic breast disease. II. Serum radioimmunoassayable prolactin and growth hormone and bioactive lactogenic hormones. Journal of the National Cancer Institute 78, 627-631.

Rosen, P. P., Ashikari, R. \& Thaler, H. (1977). A comparative study of some pathological features of mammary carcinoma in Tokyo, Japan and New York, USA. Cancer 39, 429434.

Ross, M. H. \& Bras, G. (1971). Lasting influence of early caloric restriction on prevalence of neoplasms in the rat. Journal of the National Cancer Institute 47, 1095-1113.

Salonen, J. T., Salonen, R., Lappetelainen, R., Mmenpaa, P. H., Alfthan, G. \& Puska, P. (1985). Risk of cancer in relation to serum concentrations of selenium and vitamins $\mathbf{A}$ and $\mathbf{E}$ : Matched use control analysis of prospective data. British Medical Journal 290, 417-420.

Seifter, E., Rettura, G. \& Levenson, S. M. (1984). Supplemental $\beta$-carotene (BC): Prophylactic action against 7,12 dimethylbenz $(\alpha)$ anthracene (DMBA) carcinogenesis. Federation Proceedings, Federation of American Societies of Experimental Biology 43, 662.

Shultz, T. D., Wilcox, R. B., Speuhler, J. M. \& Howie, B. J. (1987). Dietary and hormonal interrelationships in premenopausal women: evidence for a relationship between dietary nutrients and plasma prolactin levels. American Journal of Clinical Nutrition 46, 905-911.

Sidell, N., Altman, P., Haussler, M. A. \& Seeger, R. C. (1983). Effects of retinoic acid (RA) on the growth of phenotypic expressions of several human neuroblastoma cell lines. Experimental Cell Research 148, 21-30.

Sies, H. (1990). Antioxidant defense systems. Proceedings of the International Conference on Antioxidant Vitamins and $\beta$-Carotene in Disease Prevention. London: In the press.

Siiteri, P. K. (1987). Adipose tissue as a source of hormones. American Journal of Clinical Nutrition 45, $277-282$.

Simpson. E. R. \& Mendelson. C. R. (1987). Effect of aging and obesity on aromatase activity of human adipose cell. American Journal of Clinical Nutrition 45, 290-95.

Soini, I. (1977). Risk factors of breast cancer in Finland. International Journal of Epidemiology 6, 365-373.

Sporn, M. B., Dunlop, N. M., Newton, D. L. \& Smith, J. M. (1976). Prevention of chemical carcinogenesis by vitamin $\mathrm{A}$ and its synthetic analogs (retinoids). Federation Proceedings, Federation of American Societies of Experimental Biology 35, 1332-1338.

Sporn, M. B. \& Roberts, A. B. (1984). Role of retinoids in differentiation and carcinogenesis. Journal of the National Cancer Institute 73, 1381-1387.

Stähelin, H. B. \& Buess, E. (1982). Vitamin A and cardiovascular risk factors, and mortality. Lancet i, $394-395$.

Stich, H. F., Rosin, M. \& Vallejera, M. O. (1984a). Reduction with vitamin A and $\beta$-carotene administration of proportion of micronucleated buccal mucosal cells in Asian betal nut and tobacco chewers. Lancet $\mathbf{i}$, $1204-1206$.

Stich, H. F., Stich, W., Rosin, M. P. \& Vallejera, M. O. (1984b). Use of the micronucleous test to monitor the effect 
of vitamin A, $\beta$-carotene and conthaxanthin on the buccal mucosa of betal nut/tobacco chewers. International Journal of Cancer 34, 745-750.

Toniolo, P., Riboli, E., Protta, F., Charrel, M. \& Cappa, A. D. M. (1989). Calorie providing nutrients and risk of breast cancer. Journal of the National Cancer Institute 81, 278-286.

Tyler, H. A., Notley, R. G., Schweitzer, F. A. W. \& Dickerson, J. W. T. (1986). Vitamin A status and bladder cancer, European Journal of Surgical Oncology 12, 35-41.

Uriel, J. (1979). Retrodifferentiation and the fetal patterns of gene expression in cancer. Advances in Cancer Research 29, 127-174.

Verreault, R., Bresson, J., Deschenes, L., Nand, F., Meyer, F. \& Belanger, L. (1988). Dietary fat in relation to prognostic indicators in breast cancer. Journal of the National Cancer Institute 80, 819-825.

de Waard, F. (1975). Breast cancer incidence and nutritional status with particular reference to body weight and height. Cancer Research 35, 33513356.

Wagner, D. A., Naylor, P. H., Kim, U., Shea, W., Ip, C. \& Margot, M. M. (1982). Interaction of dietary fat and the thymus in the induction of mammary tumors by 7,12-dimethylbenz( $\alpha$ )anthracene. Cancer Research 42 , 1266-1273.

Wahrendorf, J. (1989). Dietary fat, dietary cholesterol and obesity as risk factors for colorectal cancer, kidney cancer and other tumors. In Diet and the Aetiology of Cancer. European School of Oncology Monographs, pp. 13-19 [A. B. Miller, editor]. Heidelberg: Springer-Verlag.

Wahrendorf, J., Munoz, N., Jian-Bang, L., Thurnham, D. I., Grespi, M. \& Bosch, F. X. (1988). Blood retinol and zinc riboflavin status in relation to precancerous lesions of the esophagus: findings from a vitamin interaction trial in the People's Republic of China. Cancer Research 48, 2280-2283.

Wald, N., Boreham, J. \& Bailey, A. (1986). Serum retinol and subsequent risk of cancer. British Journal of Cancer 54, 957961.

Wald, N. J., Boreham, J., Hayward, J. L. \& Bulbrook, R. D. (1984). Plasma retinol, $\beta$ carotene and vitamin E levels in relation to future risk of breast cancer. British Journal of Cancer 49, 321-324.

Walk, N., Idle, M., Boreham, J. \& Bailey, A. (1980). Low serum vitamin A and subsequent risk of cancer. Preliminary results in a prospective study. Lancet ii, 813-815.

Weinstein, l. B., Gattoni-Celli, S., Kirschmeier, P., Hsiao, W., Horowitz, A. \& Jeffrey, A. (1984). Cellular targets and host genes in multi-stage carcinogenesis. Federation Proceedings 43, 22872294.

Welsch, C. W. (1985). Host factors affecting the growth of carcinogen-induced rat mammary carcinomas: a review and tribute to Charles Brenton Huggins. Cancer Research 45, 3415-3443.

Welsch, C. W. (1986). Interrelationships between dietary fat and endocrine processes in mammary gland tumorigenesis. In Dietary Fat and Cancer, pp. 623654 [A. Rogers, D. Birt, E. Mettlin and C. Ip, editors]. New York: Alan R. Liss Inc.

Welsch, C. W. (1987). Enhancement of mammary tumorigenesis by dietary fat: review of potential mechanisms. American Journal of Clinical Nutrition 45, $192-202$.

Welsch, C. W. \& Aylsworth, C. F. (1983). Enhancement of murine mammary tumorigenesis by feeding high levels of dietary fat: a hormonal mechanism? Journal of the National Cancer Institute 70, $215-221$.

Welsch, C. W., DeHoog, J. V., Scieszka, K. M. \& Aylsworth, C. F. (1984). Retinoid feeding, hormone inhibition, and/or immune stimulation and the progression of $N$-methyl- $N$-nitrosourea-induced rat mammary carcinoma: suppression by retinoids of peptide hormone-induced tumor cell proliferation in vivo and in vitro. Cancer Research 44, 166.171.

Welsch, C. W., DeHoog, J. V., O'Connor, D. H. \& Sheffield, L. G. (1985). Influence of dietary fat levels on development and hormone responsiveness of the mouse mammary gland. Cancer Research 45, 147-154.

Wetherall, N. T., Mitchell, W. M. \& Halter, S. A. (1984). Antiproliferative effect of vitamin A on xenotransplanted CAMA-15 cells. Cancer Research 44, 2393-2397.

Wicha, M. S., Liotta, L. A. \& Kidwell, W. R. (1979). Effects of free fatty acids on the growth of normal and neoplastic rat mammary epithelial cells. Cancer Research 39, 426-435.

Willett, W. C. (1987). Implications of total energy intake for epidemiologic studies of breast and large bowel cancer. American Journal of Clinical Nutrition 45, 354-360.

Willett, W. C., Browne, M. L. \& Bain, C. (1985). Relative weight and risk of breast cancer among premenopausal women. American Journal of Epidemiology 122, 731-740.

Williams, C. M. \& Dickerson, J. W. T. (1987). Dietary fat, hormones and breast cancer: the cell membrane as a possible site of interaction of these two risk factors. European Journal of Surgical Oncology 13, 89-104.

Williams, C. M. \& Maunder, K. (1990). Comparative effects of $\omega 9, \omega 6$ and $\omega 3$ dietary fatty acids on mammary tumor incidence and membrane phospholipid fatty acid compositions. Biochemistry Society Transactions. (In the Press.)

Williams, C. M., Maunder, K. \& Theale, D. (1989). The effect of a low-fat diet on luteal phase prolactin and oestradiol concentrations and erythrocyte phospholipids in normal premenopausal women. British Journal of Nutrition 61, 651 661. 
Wolbach, S. B. \& Howe, P. R. (1925). Tissue changes following deprivation of fat soluble vitamin A. Journal of Experimental Medicine 47, $753-777$.

Wu, A. H., Henderson, B. E., Pike, M. E. \& Yu, M. C. (1985). Smoking and other risk factors for lung cancer in women. Journal of the National Cancer Institute 74, 747-751.

You, W.-C., Blot, W. J., Chang, Y.-S., Ershow, A., Tang, Z. T., An, Q., Henderson, B. E., Fraumeni, J. F. \& Wang, T.-G. (1989). Allium vegetables and reduced risk of stomach cancer. Journal of Nutrition Cancer Institute 81, 162-164.

Ziegler, R. G., Mason, T. J., Stemhagen, A., Hoover, R., Schoenberg, J. B., Gridley, G., Virgo, P. W., Altmans, R. \& Fraumeni, J. F. (1984). Dietary carotene and vitamin A and risk of lung cancer among white men in New Jersey. Journal of the National Cancer Institute 73, 1429-1435. 